\title{
Q pili enhance the attachment of Moraxella bovis to bovine corneas in vitro
}

\author{
W. W. Ruehl, ${ }^{1,2 *}$ C. Marrs, ${ }^{3}$ M. K. Beard, ${ }^{4}$ \\ V. Shokooki, ${ }^{2}$ J. R. Hinojoza, ${ }^{2}$ S. Banks, ${ }^{1}$ D. Bieber ${ }^{2}$ \\ and J. S. Mattick ${ }^{5}$ \\ Departments of ${ }^{1}$ Pathology and ${ }^{2}$ Comparative Medicine, \\ Stanford University School of Medicine, Stanford, \\ California USA. \\ ${ }^{3}$ Department of Epidemiology, School of Epidemiology \\ and Public Health, University of Michigan, Ann Arbor, \\ Michigan, USA. \\ ${ }^{4}$ Department of Animal Health, The University of Sydney, \\ Camden, New South Wales, Australia. \\ ${ }^{5}$ Centre for Molecular Biology and Biotechnology, \\ University of Queensland, St Lucia, Queensland, \\ Australia.
}

\section{Summary}

Moraxella bovis, the causative agent of infectious bovine keratoconjunctivitis, exhibits several virulence factors, including pili, haemolysin, leukotoxin, and proteases. The pili are filamentous appendages which mediate bacterial adherence. Prior studies have shown that Q-piliated $M$. bovis Epp63 are more infectious and more pathogenic than I-piliated and nonpiliated isogenic variants, suggesting that $Q$ pili per se, or traits associated with Q-pilin expression, promote the early association of Q-piliated bacteria with bovine corneal tissue. In order to better evaluate the role of $\mathbf{Q}$ pili in $\boldsymbol{M}$. bovis attachment, several $\boldsymbol{M}$. bovis strains and a recombinant $\boldsymbol{P}$. aeruginosa strain which elaborates $\boldsymbol{M}$. bovis $\mathbf{Q}$ pili but not $\boldsymbol{P}$. aeruginosa PAK pili, were evaluated using an in vitro corneal attachment assay. For each strain tested, piliated organisms attached better than non-piliated bacteria. $M$. bovis Epp63 Q-piliated bacteria adhered better than either the I-piliated or non-piliated isogenic variants. Finally, recombinant $\boldsymbol{P}$. aeruginosa organisms elaborating $\boldsymbol{M}$. bovis $Q$ pili adhered better than the parent $\boldsymbol{P}$. aeruginosa strain which did not produce $M$. bovis pili. These results indicate that the presence of pili, especially $Q$ pili, enhances the attachment of bacteria to bovine cornea in vitro.

Received 18 November 1991; revised 16 July 1992; accepted 16 September 1992. *For correspondence: Deprenyl Animal Health Inc., 8000 West 110th Street, Suite 115, Overland Park, Kansas 66210, USA. Tel. (913) 338 2120; Fax (913) 3383804
Introduction

Moraxella bovis is the primary cause of infectious bovine keratoconjunctivitis (IBK), a highly contagious ocular disease of cattle that can result in temporary (or occasionally permananent) blindness (Hughes and Pugh, 1970). Haemolysin and pili have been established as $M$. bovis virulence factors (Pugh and Hughes, 1968; Pedersen et al., 1972). The pili are surface appendages of the bacterium composed of repeating, homologous polypeptide subunits termed pilin. The pili of $M$. bovis are classified as type 4 , and the pilin molecule contains a methylated phenylalanine ( $\mathrm{mPhe}$ ) residue at the amino terminus (Mattick et al., 1987). We have previously described, characterized, and sequenced two distinct pilin molecules, termed I and $Q$, from M. bovis strain Epp63 (Ruehl et al., 1988) and have also cloned and sequenced both pilin genes (Marrs et al., 1985; Fulks et al., 1990).

Type 4 pili are also found on Moraxella nonliquefaciens (Froholm and Sletten, 1977), Neisseria gonorrhoeae (Hermodson et al., 1978; Schoolnik et al., 1984), Neisseria meningitidis (Hermodson et al., 1978), Bacteriodes nodosus (McKern et al., 1983; 1985), and Pseudomonas aeruginosa (Sastry et al., 1983). The pilin subunits of these species range in size from 145 to 160 amino acids and are translated as prepilin. Prepilin has a six or seven residue leader sequence which when cleaved leaves the modified amino acid, methylphenylalanine, as the first reside of the mature protein (Bradley, 1980; Mattick et al., 1987; Ruehl et al., 1988). The 32 residue amino-terminal regions of all type $4 \mathrm{mPhe}$ pilins exhibit at least $90 \%$ homology and are very hydrophobic. The carboxy-terminal two-thirds of these subunits, however, is relatively hydrophilic and has many variable and hypervariable domains. As such, this region is the source of both structural and antigenic variations between species (Mattick et al., 1987).

It appears that the hydrophobic amino-terminal region may have a dual function. First, it has been proposed that it acts, perhaps in conjunction with the short leader sequence, as a signal sequence marking the peptide for transport to the cell membrane (Elleman and Hoyne, 1984). Second, it has been hypothesized that the region is involved in pili morphogenesis. There have been two mechanisms proposed for involvement of this region in morphogenesis: the region could be responsible for subunit-subunit interactions during pili assembly (Hermodson et al., 1978; McKern et al., 1983; Sastry et al., 


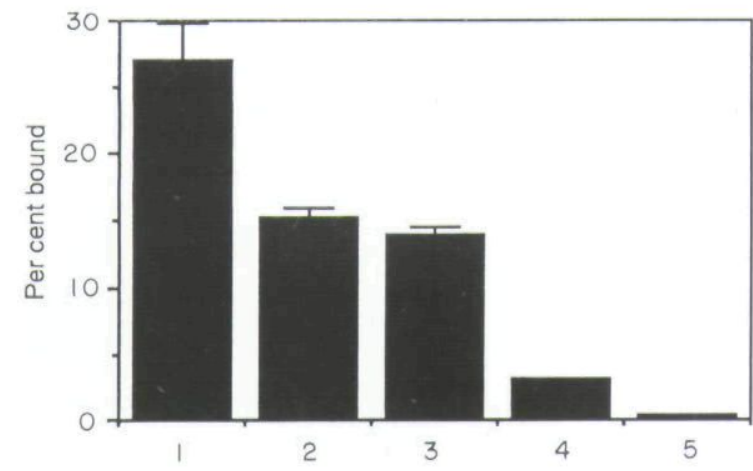

Fig. 1. Attachment in vitro of labelled $M$. bovis and $P$. aeruginosa to bovine corneal epithelium. Various piliated or non-piliated $M$. bovis and $P$. aeruginosa strains were incubated with intact bovine corneas. Details of the experimental methods and data analysis are in the text. 1 , Q-piliated $M$. bovis Epp63; 2, recombinant $P$. aeruginosa which expresses $M$. bovis Epp63 Q pili; 3, I-piliated M. bovis Epp63; 4, non-piliated $M$. bovis Epp63; 5, PAK-piliated $P$. aeruginosa. The error bars indicate \pm 2 standard deviations.

1983); and/or the amino-terminal region might interact with other essential factors involved in the assembly system. The second hypothesis was suggested on the basis of the highly conserved sequences in this region between the various bacterial species expressing type 4 pili, and is supported by the fact that $B$. nodosus pili and $M$. bovis pili can be assembled from cloned pilin genes expressed by recombinant $P$. aeruginosa (Mattick et al., 1987; Beard et al., 1990).

Attachment of pathogenic $M$. bovis to the bovine corneal epithelial surface is an early (probably the first) event leading to colonization, then to infection and clinical disease. This attachment process appears to be mediated, at least in part, by the pili which are elaborated on the bacterial cell surface. It has been observed that piliated $M$. bovis attach better to bovine corneas in vitro than do non-piliated bacteria of the same strain (Jackman and Rosenbusch, 1984). Furthermore, piliated M. bovis cause disease in the experimentally inoculated eyes of calves, while non-piliated isogenic variants do not (Ruehl et al., 1988). Additionally, the Q-piliated variant of strain Epp63 was found to be significantly more infectious for experimentally inoculated eyes than I-piliated or non-piliated variants of Epp63. These results indicated that $Q$ pili per se, or traits associated with Q-pilin expression, promote the early association of Q-piliated bacteria with bovine corneal tissue.

We have constructed a recombinant $P$. aeruginosa strain which expresses $M$. bovis Epp63 $Q$ pilin and elaborates Q-pili filaments to the exclusion of the normal indigenous Pseudomonas (PAK) pili (Beard et al., 1990). We then compared this recombinant $P$. aeruginosa with the parent, non-piliated $P$. aeruginosa strain and various $M$. bovis strains for their ability to adhere to intact bovine corneas in vitro.

\section{Results and Discussion}

Data regarding attachment of $M$. bovis, parent $P$. aeruginosa, and recombinant $P$. aeruginosa bacteria to bovine corneas is presented in Fig. 1. The previous finding (Jackman and Rosenbusch, 1984) that piliated M. bovis $118 \mathrm{~F}$ attached to corneas significantly better than nonpiliated bacteria was confirmed for two additional strains, Epp63 and Tifton-1, suggesting that this is a general phenomenon for $M$. bovis.

It is apparent in Fig. 1 that $M$. bovis Q piliated Epp63 bacteria attached significantly better than I-piliated or non-piliated isogenic variants of the same strain. This greater adherence capability correlates well with the prior observation that Q-piliated organisms are significantly more infectious than I-piliated or non-piliated variants of the same strain when inoculated into the eyes of calves (Ruehl et al., 1988; Lepper and Power, 1988), and suggests an attachment role for $Q$ pili per se, or for some factor associated with Q-piliation.

Figure 1 also shows that a recombinant $P$. aeruginosa bacteria which elaborates $M$. bovis $Q$ pili, but which no longer expresses PAK pili, attached significantly better than the PAK-pili-expressing $P$. aeruginosa parent strain. The enhancement of attachment provided by $Q$ pili was greater for $M$. bovis than for $P$. aeruginosa bacteria. The molecular basis for this is unknown but might be related to the fact that the recombinant organisms apparently express fewer pili per bacterial cell than the Q-piliated $M$. bovis (Fig. 2). Alternatively, other pilus-associated or co-regulated adhesins may be present in Q-piliated $M$. bovis but absent from the Q-piliated recombinant $P$. aeruginosa that contains only the Q-pilin subunit gene from M. bovis (Beard et al., 1990). Yet another possible explanation is that the assembly or presentation of the $Q$ pilus is slightly different in $P$. aeruginosa compared with the native $Q$ pilus, and that this could result in the reduced adherence of the recombinant.

There are now several examples of Escherichia coli pili in which the adhesive molecule is a minor pilus component separate from the major structural subunit (Lindberg et al. 1984; Klemm and Christiansen, 1987). In contrast, the evidence to date for type 4 piliated bacteria has indicated that the major structural subunit is also the adhesin. Irvin et al. (1989) and Lee et al. (1989) have reported that the adherence of $P$. aeruginosa PAK-piliated bacteria to human epithelial cells is directly attributable to the pilin subunit molecule. There is also some evidence that the pili of $N$. gonorrhoeae is the adhesin (Schoolnik et al., 1984; Rothbard et al., 1985). In agreement with the above 

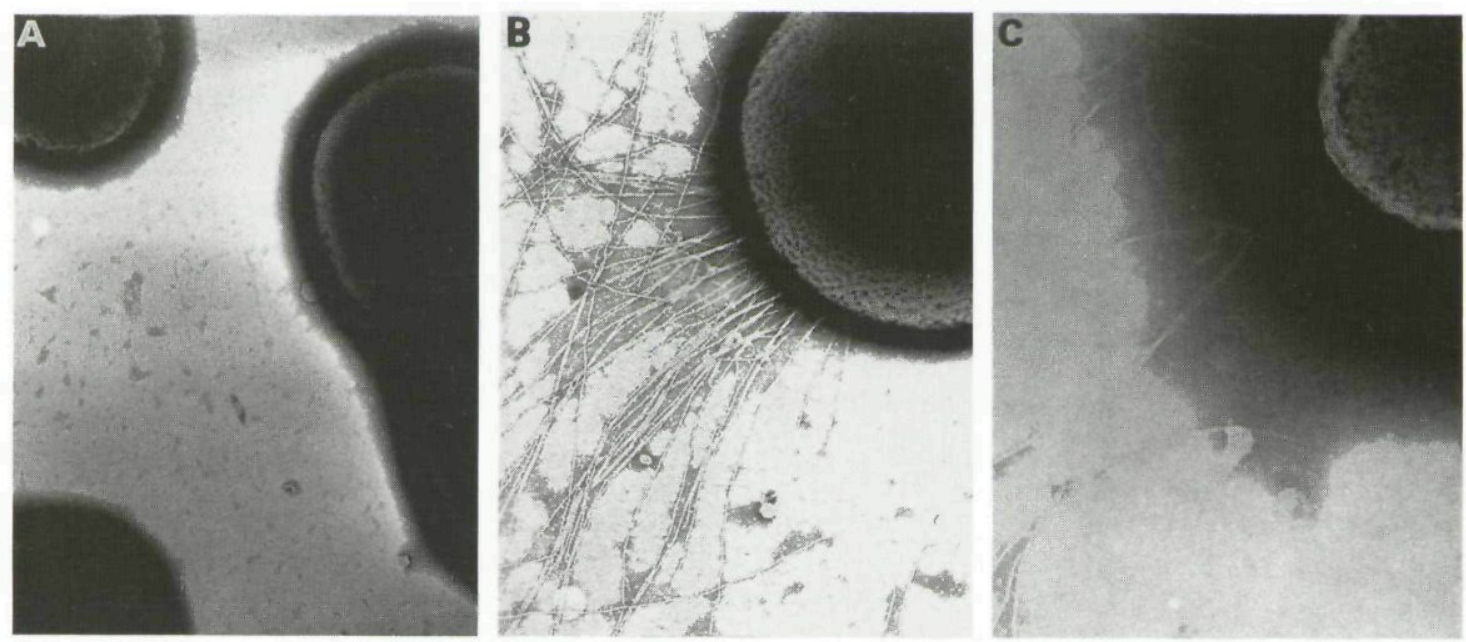

Fig. 2. Transmission electron micrographs of piliated and non-piliated bacteria. Organisms were grown $20-24 \mathrm{~h}$ at $37^{\circ} \mathrm{C}$ on $\mathrm{GC}$ or $\mathrm{L}$-agar, then transferred to copper grids, negatively stained with $1 \%$ phosphotungstate and photographed using a transmission electron microscope. Strain: $A$, non-piliated $M$. bovis Epp63, ×12000; B, Q-piliated M. bovis Epp63, ×18000; C, recombinant $P$. aeruginosa which expresses $M$. bovis Epp63 Q pili, $\times 18000$.

results, this paper provides evidence the $M$. bovis Q-pilimediated adherence must be a direct result of the presence of the Q-pilin molecule.

\section{Experimental procedures}

\section{Microorganisms}

The bacterial strains used in this study were: M. bovis Epp63 (non-piliated, I-piliated, and Q-piliated isogenic variants), $M$. bovis Tifton-1 (piliated and non-piliated), $P$. aeruginosa recombinant PAK/2Pfs (MXB/Mxb6) which express $M$. bovis Epp63 Q pilin, but not PAK pilin, and exhibits plasmid-mediated resistance to carbenicillin (Beard et al., 1990), and the parental P. aeruginosa strain PAK/2Pfs (ATCC 53308) (Bradley, 1974) which express PAK pilin and fails to grow in the presence of carbenicillin.

Solid media for cultivating microorganisms and performing colony counts consisted of blood agar (Remel), GC (gonococcal) agar base (Difco Laboratories) to which was added 2\% (v/v) IsoVitaleX (BBL Microbiology Systems), and L-agar with or without $75 \mu \mathrm{g} \mathrm{ml}^{-1}$ carbenicillin added. The expression of pilin and the presence of pili were confirmed by immunoblotting (Beard et al., 1990) and electron microscope inspection (Fig. 2) of phosphotungstate-stained organisms, respectively.

\section{Preparation of radiolabelled bacteria}

For each strain, bacterial growth from two plates was gently suspended in $750 \mu \mathrm{l}$ of ice-cold Hanks Balanced Salt Solution (HBSS) (Sigma) and $250 \mu \mathrm{l}$ of the following salt solution: $50 \mathrm{mM}$ Tris- $\mathrm{HCl}, \mathrm{pH} 8,50 \mathrm{mM} \mathrm{Na}$ acetate, $140 \mathrm{mM} \mathrm{NaCl}, 5 \mathrm{mM} \mathrm{CaCl}_{2}$, $4 \mathrm{mM} \mathrm{KCl}, 2 \mathrm{mM} \mathrm{MgCl}_{2}, 1 \%$ bovine serum albumin (BSA), and $1 \%$ glycerol. To determine the concentration of each of these bacterial suspensions, a $1 \mu \mathrm{l}$ aliquot of each suspension was diluted 1:106, inoculated onto a blood agar plate, incubated overnight at $37^{\circ} \mathrm{C}$, and the colonies counted. Also, a single drop of each bacterial suspension was transferred to a microscope slide and Gram-stained. Ten fields were examined using $\times 1000$ magnification to determine the number of bacterial aggregates present. If more than five bacterial aggregates were counted, the suspension was discarded.

The remainder of each bacterial suspension was labelled by incubation with $20 \mu \mathrm{Ci} \mathrm{ml}^{-1}$ of L-[ $\left[4^{\prime} 5-^{-3} \mathrm{H}\right]$-proline (Amersham) for $2 \mathrm{~min}$ at $22^{\circ} \mathrm{C}$, followed by incubation with $20 \mu \mathrm{g} \mathrm{ml}^{-1}$ unlabelled proline under the same conditions.

\section{Preparation of corneas}

Adult cattle eyes were obtained from a local slaughter house and were transported in ice-cold HBSS to which $100 \mu \mathrm{g} \mathrm{ml}^{-1}$ gentamicin had been added. Only corneas without visible opacity were used. Each entire cornea was placed on a flat surface with the epithelial cell layer facing upward. A second matching plastic surface containing holes was placed on top thereby forming wells: the floor of each well thus consisted exclusively of cornea epithelium. The wells were filled with HBSS until use in the adherence assay, at which time the HBSS was removed and the tissue was washed twice with phosphate-buffered saline (PBS).

\section{Adherence assay}

The adherence assay was a modification of one described by Jackman and Rosenbusch (1984). One-hundred microlitres of the radiolabelled bacterial suspension were added to each well and the apparatus was incubated $60 \mathrm{~min}$ at $37^{\circ} \mathrm{C}$ in a moist environment. The reaction was terminated by removal of the unattached bacteria and the wells washed with PBS. Using a biopsy skin punch a $9 \mathrm{~mm}$ diameter piece of exposed cornea was harvested from each well, transferred to $1 \mathrm{ml}$ of $2 \%$ SDS and boiled for 10 $\mathrm{min}$. The tubes were centrifuged $2 \mathrm{~min} ; 100 \mu \mathrm{l}$ of the supernatant from each tube (containing radiolabelled bacterial components) were added to $3 \mathrm{ml}$ of scintillation fluid, and radioactivity determined as counts per minute (c.p.m.) using a Beckman 8000 
beta counter. In each assay, the background radioactivity (c.p.m.) was determined for one well which contained buffer only. The percentage of bacteria attached was calculated by the following formula:

$$
\begin{aligned}
& \text { (cfu attached to cornea) - (cfu on } \\
& \text { background cornea) } \\
& \text { (cfu added to experimental cornea) }
\end{aligned}
$$

The results were derived from three to five experiments with each microorganism. The significance of the differnces in attachment between strains was determined using Students $t$-test with paired values and a two-tailed hypothesis.

\section{Acknowledgements}

This work was supported in part by NIH Eye Institute grant RO1 EY07125-01 (C.M.) and USDA grant 87-CRCR-1-2403 (W.W.R.).

\section{References}

Beard, M.K., Mattick, J.S., Moore, L.J., Mott, M.R., Marrs, C.F., and Egerton, J.R. (1990) Morphogenic expression of Moraxella bovis fimbriae (pili) in Pseudomonas aeruginosa. J Bacteriol 172: 2601-2607.

Bradley, D.E. (1974) The adsorption of Pseudomonas aeruginosa pilus-dependent bacteriophages to a host mutant with nonretractile pili. Virology 58: 149-163.

Bradley, D.E. (1980) The function of Pseudomonas aeruginosa PAO pili: twitching motility. Can J Microbiol 26: 146-154.

Elleman, T.C., and Hoyne, P.A. (1984) Nucleotide sequence of the gene encoding pilin of Bacteroides nodosus, the causal organism of ovine footrot. J Bacteriol 160: 1184-1187.

Froholm, L.O., and Sletten, K. (1977) Purification and N-terminal sequence of a fimbrial protein from Moraxella nonliquifaciens. FEBS Lett 73: 29-32.

Fulks, K.A., Marrs, C.F., Stevens, S.P., and Green, M.R. (1990) Sequence analysis of the inversion region containing the pilin genes of Moraxella bovis. J Bacteriol 172: 310-316.

Hermodson, M.A., Chen, K.C.S., and Buchanan, T.M. (1978) Neisseria pili proteins: amino terminal amino acid sequences and identification of an unusual amino acid. Biochemistry 17: 442-445.

Hughes, D.E., and Pugh, G.W. (1970) A five year study of IBK in a beef herd. J Am Vet Med Assoc 157: 443-451.

Irvin, R.T., Doig, P., Lee, K.K., Sastry, P.A., Paranchych, W., Todd, T., and Hodges, R.S. (1989) Characterization of the Pseudomonas aeruginosa pilus adhesin: confirmation that the pilin structural protein subunit contains a human epithelial cell-binding domain. Infect Immun 57: 3720-3726.

Jackman, S.H., and Rosenbusch, R.F. (1984) In vitro adherence of
Moraxella bovis to intact corneal epithelium. Curr Eye Res 3: 1107-1112.

Klemm, P., and Christiansen, G. (1987) Three fim genes required for the regulation of length and mediation of adhesion of $E$. coli type 1 fimbriae. Mol Gen Genet 208: 439-445.

Lee, K.K., Doig, P., Irvin, R.T., Paranchych, W., and Hodges, R.S. (1989) Mapping the surface regions of Pseudomonas aeruginosa PAK pilin: the importance of the $\mathrm{C}$-terminal region for adherence to human buccal epithelial cells. Mol Microbiol 3: 1493-1499.

Lepper, A.W., and Power, B.E. (1988) Infectivity and virulence of Australian strains of Moraxella bovis for the murine and bovine eye in relation to pilus serogroup sub-unit size and degree of piliation. Austr Vet J 65: 305-309.

Lindberg, F.P., Lund, B., and Normark, S. (1984) Genes of pyelonephritogenic $E$. coli required for digalactoside-specific agglutination of human cells. EMBO J 3: 1167-1173.

Marrs, C.F., Schoolnik, G., Koomey, J.M., Hardy, J., Rothbard, J., and Falkow, S. (1985) Cloning and sequencing of a Moraxella bovis pilin gene. J Bacteriol 163: 132-139.

Mattick, J.S., Bills, M.M., Anderson, B.J., Dalrymple, B., Mott, M.R., and Egerton, J.R. (1987) Morphogenic expression of Bacteriodes nodosus fimbriae in Pseudomonas aeruginosa. $J$ Bacteriol 169: 33-41.

McKern, N.M., O'Donnell, I.J., Inglis, A.S., Stewart, D.J., and Clark, B.L. (1983) Amino acid sequences of pilin from Bacteroides nodosus (Strain 198), the causative agent of ovine footrot. FEBS Lett 164: 149-153.

McKern, N.M., O'Donnell, I.J., Stewart, D.J., and Clark, B.L. (1985) Primary structure of pilin protein from Bacterioides nodosus (strain 216): comparison with the corresponding protein from strain 198. J Gen Microbiol 131: 1-6.

Pedersen, K.B., Froholm, L.O., and Bovre, K. (1972) Fimbriation and colony type of Moraxella bovis in relation to conjunctival colonization and development of keratoconjunctivitus in cattle. Acta Pathol Microbiol Scand Sect B Microbiol 80: 911-918.

Pugh, G.W., and Hughes, D.E. (1968) Experimental bovine infectious keratoconjunctivitus caused by sunlamp irradiation and Moraxella bovis infection: Correlation of hemolytic ability and pathogenicity. Am J Vet Res 29: 835-839.

Rothbard, J.B., Fernandez, R., Wang, L., Teng, N.N., and Schoolnik, G.K. (1985) Antibodies to peptides corresponding to a conserved sequence of gonococcal pilins block bacteria adhesin. Proc Natl Acad Sci USA 82: 915-919.

Ruehl, W.W., Marrs, C.F., Fernandez, R., Falkow, S., and Schoolnik, G.K. (1988) Purification, characterization, and pathogenicity of Moraxella bovis pili. J Exp Med 168: 9831002.

Sastry, P.A., Pearlstone, J.R., Smillie, L.B., and Paranchych, W. (1983) Amino acid sequence of pilin isolated from Pseudomonas aeruginosa PAK. FEBS Lett 151: 253-256.

Schoolnik, G.K., Fernandez, R., Tai, Y.Y., Rothbard, J., and Gotschlich, E.C. (1984) Gonococcal pili: primary structure and receptor binding domain. J Exp Med 159: 1351-1370. 
This document is a scanned copy of a printed document. No warranty is given about the accuracy of the copy. Users should refer to the original published version of the material. 